\title{
Dollarizing The Cash Conversion Cycle
}

\author{
Richard B. Griffin, University of Tennessee at Martin, USA \\ B. Wynne Griffin, Fareva, USA \\ K. W. VanVuren, University of Tennessee at Martin, USA
}

\begin{abstract}
For most companies to be financially successful, it is critically important that operating cash flows be effectively managed. The Cash Conversion Cycle (CCC) is a traditional tool that companies use to measure the average time required for operating cash flows to cycle from cash out for the payment of payables and back to cash flow in from the collection of receivables. Knowledge that the rate their operating cash flow is speeding up or slowing down, as indicated by a decreasing or increasing CCC, while useful information, is of limited value to the company. The CCC indicates nothing about the absolute dollar amount of the cash flow.
\end{abstract}

This paper illustrates a method by which the current year actual CCC and the next year target $C C C$, along with a few other items of data, can be used to forecast the dollar amount of the next year's operating cash flows. The extension of the CCC to enable it to help forecast the dollar amount of operating cash flows makes the CCC more useful to companies attempting to effectively manage operating cash flows.

Keywords: Cash Conversion Cycle; Statement of Cash Flows

\section{INTRODUCTION - MOTIVATION FOR THIS PAPER}

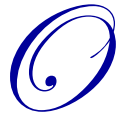

ne of the most critical factors contributing to the financial success of most companies is the accurate measurement, understanding, and effective management of operating cash flows. All of the firm's cash flows (operating, investing, and financing activities) are occurring simultaneously; however, it is reasonable to say that it is the operating cash flow that is of foremost importance. In managing the firm, one might logically view the relationship of the three types of cash flow activities as occurring in the following sequential order. First, on a day-to-day basis, the firm, as an economic competitor, must go about its business of delivering its goods or services, at a profit, to a willing demanding market. Positive cash flow ensues from the fruition of sales and negative cash flows occur when inputs/resources are paid. In a profitable company, more cash will flow in from operations than cash will flow out from operations and positive net operating cash flows ultimately result. Second, the company has to simultaneously attend to its investment needs - the acquisition of fixed assets and other infrastructure needed to perpetuate the firm's ongoing into the future. The positive operating cash flows may or may not be sufficient at any given point in time to cover investing cash flow requirements. Regardless, financing cash flows can be viewed chronologically as a third phase or as a "plug." If operating cash flow is sufficient to cover investing cash flow needs, the firm can use the excess cash to pay down debt, retire equity, increase cash dividend payout, build cash reserves, etc. If operating cash flow is not adequate to meet investing cash flow needs, the firm will have to obtain the necessary cash by incurring additional debt or issuing additional equity. The essential point is that operating cash flow is truly the "engine" driving the firm's total cash flow cycle. Thus, understanding and effectively managing the firm's operating cash flow is of primary importance to the financially successful company.

This paper demonstrates how a popular device called the "cash conversion cycle" (hereafter referred to as the CCC) can be effectively used to forecast the dollar amount of operating cash flow in future periods. Most simply put, the CCC can be defined as the number of days between the cash payment for the purchase of inventory and the cash receipt from the sale of said product. Computationally, the CCC can be constructed as days sales outstanding in receivables (DSO) plus days cost of goods sold outstanding in inventory (DIO) minus days purchases outstanding in payables (DPO). Notice that the logical interpretation of the CCC calculation, being as it is an expression of time, is that the shorter the CCC, the better (the shorter the CCC; i.e., the fewer the number of days, the quicker the flow of 
cash). This is useful information, to a degree, but it says nothing about the dollar amount of cash flow over the computed period of time. The paper explains a technique by which the CCC (more specifically, its components of DSO, DIO, and DPO), along with an assumed dollar amount of credit sales and cost of goods sold (CGS), can be used to forecast a dollar amount of operating cash flow.

To demonstrate the logical connection between the CCC and dollarizing the amount of operating cash flow, this paper will demonstrate the inter-connection of several traditional accounting constructs and changes in the balance of the cash account on the balance sheet. To do so, the paper proceeds in the following manner. First is a demonstration of how, using information from the income statement and balance sheet, receivables $(A / R)$, inventory (INV), and payables (A/P) turnovers can be computed. Then the paper shows how the turnovers can easily be converted to expressions of DSO, DIO, and DPO (the components of the CCC), and vice versa. Next, a demonstration, via algebraic manipulation, of how using income statement information and reciprocals of turnovers, year-end to year-end changes in $\mathrm{A} / \mathrm{R}$, INV, and $\mathrm{A} / \mathrm{P}$ can be computed. This is followed by a review of the indirect method's logic in constructing the statement of cash flows, and, finally, a demonstration tying all this together and using a numerical example of how a forecast of the dollar amount of operating cash flow can be computed requiring merely assumptions of credit sales, CGS, and components of the CCC. The paper concludes with a summary and a brief discussion of limitations and implications for future research.

\section{USING TURNOVERS TO COMPUTE THE COMPONENTS OF THE CCC}

In general, the term "turnover," as used in the context of financial analysis, entails associating an income statement flow with a logically related account on the balance sheet. Specifically, the flow of credit sales on the income statement can be related to the balance of $A / R$ on the balance sheet, and the flow of CGS on the income statement can be separately related to both the balances of INV and A/P on the balance sheet. The conventional calculation of turnover ratios is to place the income statement flow in the numerator and the balance sheet balance in the denominator. Thus, $\mathrm{A} / \mathrm{R}$ turnover $=($ credit sales/ending balance $\mathrm{A} / \mathrm{R})$; inventory turnover $=(\mathrm{CGS} / \mathrm{ending}$ balance INV); and payables turnover $=($ CGS/ending balance $\mathrm{A} / \mathrm{P})$. Note that the some analysts commonly use an average of the beginning and ending balance sheet account balances in the denominators; but for the methodology described in this paper, ending balance sheet account balances are used. Conventional interpretation of the A/R and INV turnovers is that the higher the turnover, the better (i.e., a higher turnover number implies a more rapid conversion of INV and A/R to cash.) Conversely, a lower A/P turnover ratio is preferred in a cash flow sense in that a lower number implies a slower rate of conversion of payables to cash out-flows.

Each of the turnovers can be easily converted to a "days outstanding" metric. Computationally, DSO = (360 days/ receivables turnover), DIO $=(360$ days/inventory turnover $)$, and DPO $=(360$ days/payables turnover $)$. Note that some analysts may use 365 or 366 days in the numerator, but a simple assumption of a fiscal year consisting of twelve equal 30-day months is sufficient for our methodology. The important thing is to consistently use the same number of annual days in all calculations.

\section{USING TURNOVERS TO COMPUTE ENDING BALANCES OF BALANCE SHEET ACCOUNTS}

From the turnover computations, as defined in the first paragraph of the prior section, note that by algebraic manipulation, given turnovers can be used to compute ending balances of certain balance sheet accounts. Specifically, ending balance of $\mathrm{A} / \mathrm{R}=$ (credit sales/receivables turnover), ending balance of inventory = CGS/inventory turnover), and ending balance of $\mathrm{A} / \mathrm{P}=(\mathrm{CGS} /$ payables $)$. Alternatively, ending balances can be expressed as a multiplicative calculation using the reciprocals of the turnovers. Therefore, ending balance of $\mathrm{A} / \mathrm{R}=$ [credit sales X (1/receivable turnover)], ending balance of inventory $=[$ CGS X (1/inventory turnover) $]$, and ending balance of payables $=[$ CGS X $(1 /$ payables turnover $)]$.

\section{ALGEBRAIC MANIPULATION TO COMPUTE THE YEAR-TO-YEAR CHANGE IN BALANCE SHEET ACCOUNT BALANCES}

Year-to-year changes in the account balances of $\mathrm{A} / \mathrm{R}, \mathrm{INV}$, and $\mathrm{A} / \mathrm{P}$, respectively, can be computed using the following formula: $\mathrm{F}-\mathrm{E}=[\mathrm{C} \times(\mathrm{D}-\mathrm{B})]+[(\mathrm{C}-\mathrm{A}) \mathrm{x} \mathrm{B}]$. This equation derives from the following relationships: 
$\mathrm{A} \times \mathrm{B}=\mathrm{E}$ and $\mathrm{C} \times \mathrm{D}=\mathrm{F}$, where:

A = income statement flow of Yr. 1

$\mathrm{B}=$ reciprocal of balance sheet account turnover for Yr. 1

$\mathrm{E}=$ balance sheet account ending balance of Yr. 1

$\mathrm{C}=$ income statement flow of Yr. 2

$\mathrm{D}=$ reciprocal of balance sheet account turnover for Yr. 2

$\mathrm{F}=$ balance sheet account balance ending balance of Yr. 2

Obviously, F-E = the change in the account balance from Yr. 1 to Yr. 2.

Computing the year-to-year change in $\mathrm{A} / \mathrm{R}$ can be illustrated using the following example. GIVEN:

Yr. 1 credit sales $=\$ 100,000$

Yr. 1 receivables turnover $=4$ (reciprocal of turn $=.25)$

Yr. 2 credit sales $=\$ 110,000$

Yr. 2 receivables turnover $=5$ (reciprocal of turn $=.20)$ so:

$\$ 100,000 \times .25=\$ 25,000$ (Yr. 1 ending balance of $\mathrm{A} / \mathrm{R}$ ) and

$\$ 110,000 \times .20=\$ 22,000$ (Yr. 2 ending balance of $A / R)$, therefore:

\begin{tabular}{c} 
Yr. $1 \rightarrow \$ 100,000 \times .25=\$ 25,000$ \\
Yr. $2 \rightarrow \$ 110,000 \times .20=\$ 22,000$ \\
\hline$\Delta s \rightarrow \$ 10,000 \times<.05>=\langle \$ 3,000\rangle$
\end{tabular}

Alternatively, using the "algebraic manipulation" to compute the change in A/R balance:

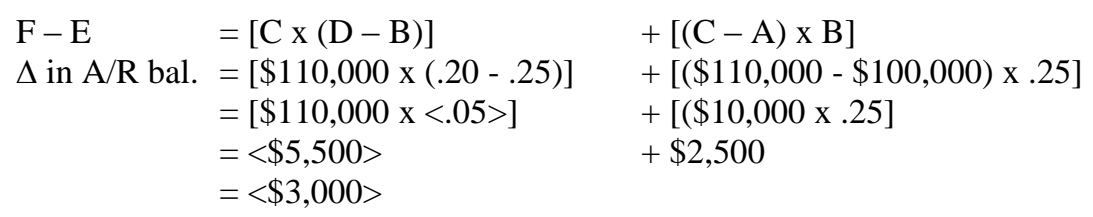

Conclusion: the change in A/R from Yr. 1 to Yr. 2 is a decrease of $\$ 3,000$. The year-to-year changes in INV and $\mathrm{A} / \mathrm{P}$ can be computed in the same manner.

\section{STATEMENT OF CASH FLOWS - INDIRECT METHOD}

To fully explain how the dollar amount of periodic operating cash flow can be calculated from two periods of credit sales, CGS, and CCC, it is necessary to briefly review the logic and mechanics of the indirect method statement of cash flows. The fundamental logic underlying the indirect method statement of cash flows is that the change in year-to-year change in cash balance can be indirectly "explained" by the year-to-year changes in all the accounts in the fundamental accounting equation (assets = liabilities + equity) other than cash. More specifically in regard to operating cash flows, changes in cash can be indirectly derived by converting the revenues and expenses of the income statement (which under GAAP are expressed on an accrual basis) to their cash basis equivalent via changes in all the current asset and liability accounts on the balance sheet. Also melding in the effect of long-term assets on the balance sheet, whose amortizations on the accrual/deferral income statement are not really cash effects, one has the following conventional construction of a simple section of operating cash flows on an indirect-method statement of cash flows:

Net Income

+ non-cash charges (e.g., depreciation)

\pm changes in current assets

\pm changes in current liabilities

$=$ Operating Cash Flow 
The paper will now illustrate, through a numerical example, how dollar amount of next year operating cash flow can be forecasted using only base year actuals and next year forecasts of credit sales, CGS, and the CCC.

\section{FORECASTING FUTURE OPERATING CASH FLOWS}

To begin the illustration, first observe the end result. Table 1 presents two years of consecutive balance sheets. In the simple example that follows, the company has no investing or financing cash flows. Therefore, the operating cash flows for Yr. 2 are positive \$57,660 (i.e., the change in the balance of the cash account from the end of Yr. 1 to the end of Yr. 2).

Table 1: Data to be used in a Numerical Example of the Statement of Cash Flows using the Indirect Method

\begin{tabular}{|c|c|c|c|}
\hline \multicolumn{2}{|l|}{ Yr. 1 - Balance Sheet } & \multicolumn{2}{|c|}{ Yr. 2-Balance Sheet } \\
\hline Cash & 77,000 & Cash & 134,660 \\
\hline Receivables (A/R) & 25,000 & Receivables & 22,000 \\
\hline Inventory & $\underline{7,000}$ & Inventory & $\underline{3,135}$ \\
\hline Total Assets & $\underline{\underline{109,000}}$ & Total Assets & $\underline{159,795}$ \\
\hline Payables (A/P) & 8,000 & Payables & 11,495 \\
\hline Equity & $\underline{101,000}$ & Equity & $\underline{148,300}$ \\
\hline Total Liabilities/Equity & $\overline{\underline{109,000}}$ & Total Liabilities/Equity & $\underline{159,795}$ \\
\hline Yr. 1 - Income Statement & & Yr. 2 & \\
\hline Sales & 100,000 & Sales & 110,000 \\
\hline Cost of Goods Sold(CGS) & $\underline{60,000}$ & Cost of Goods Sold & $\underline{62,700}$ \\
\hline Net Income & $\underline{\underline{40,000}}$ & Net Income & $\underline{47,300}$ \\
\hline
\end{tabular}
Cash Flow.

Table 2 shows the calculation of operating cash flow for Yr. 2 using the indirect method - Statement of

Table 2: Yr. 2 - Indirect Method Statement of Cash Flows

\begin{tabular}{|c|c|}
\hline \multirow{2}{*}{\multicolumn{2}{|c|}{$\begin{array}{l}\text { Net Income } \\
+ \text { non-charges such as depreciation }\end{array}$}} \\
\hline & \\
\hline + decrease in Receivables (A/R) $[\$ 25,000-\$ 22,000]$ & 3,000 \\
\hline+ decrease in Inventory $[\$ 7,000-\$ 3,135]$ & 3,865 \\
\hline+ increase in Payables $(\mathrm{A} / \mathrm{P})[\$ 8,000-\$ 11,495]$ & $\underline{3,495}$ \\
\hline$=$ Cash Flow from Operations & $\underline{\underline{57,660}}$ \\
\hline$* \Delta$ in Cash $=\$ 77,000-\$ 134,666=\$ 57,660$ & \\
\hline
\end{tabular}

The information required to forecast next year's operating cash flow is summarized in Table 3.

Table 3: Data required for Forecasting Future Operating Cash Flows

\begin{tabular}{|c|c|c|}
\hline Data required... & Last Year & Next Year \\
\hline Credit sales & Actual & Forecasted/Budgeted \\
\hline Cost of Goods Sold (CGS) & Actual & Forecasted/Budgeted \\
\hline Day Sales Outstanding in Receivables (DSO) & Actual & Forecasted/Budgeted \\
\hline Days CGS Outstanding in Inventory (DIO) & Actual & Forecasted/Budgeted \\
\hline Day Purchases Outstanding in Payables (DPO) & Actual & Forecasted/Budgeted \\
\hline
\end{tabular}

The credit sales and CGS given in Table 1 are restated in Table 4 which also shows the CCC (and its component DSO, DIO, and DPO) as implied by the two years of given income statements and balance sheets. Note that the days outstanding calculations are based on first computing a turnover using the appropriate flow income statement item in the numerator and the appropriate account ending balance sheet balance in the denominator. For 
example, the actual Yr. 1 DSO of 90 days is derived by first computing a turnover by taking the income statement flow of $\$ 100,000$ of actual credit sales and dividing it by the actual Yr. $1 \$ 25,000$ ending balance of A/R. Thus, receivable turnover $=\$ 100,000 / \$ 25,000=4.00$. Then assuming an accounting year of 12 equal 30-day months, 360 total days of the year divided by the A/R turnover of 4 equals the DSO of 90 days. The days outstanding for inventory and payables, for both years, are computed similarly - of course, using the appropriate income statement and balance accounts, respectively. Table 5 summarizes the turnovers that "translate" into their respective days outstanding calculations, given the specific balance sheets and income statements of this illustration.

\begin{tabular}{|c|c|c|}
\hline Data required... & Last Year & Next Year \\
\hline Credit sales & 100,000 & 110,000 \\
\hline \multirow[t]{2}{*}{ Cost of Goods Sold (CGS) } & 60,000 & 62,700 \\
\hline & $60 \%$ & $57 \%$ \\
\hline Day Sales Outstanding in Receivables (DSO) & 90 days & 72 days \\
\hline Days CGS Outstanding in Inventory (DIO) & $\underline{42 \text { days }}$ & 18 days \\
\hline Total & 132 days & 90 days \\
\hline Day Purchases Outstanding in Payables (DPO) & -48 days & -66 days \\
\hline Cash Conversion Cycle (CCC) & 84 days & 24 days \\
\hline
\end{tabular}

So far, this numerical example has illustrated the logical; i.e., algebraic, interconnectedness of turnover and days outstanding calculations, given two successive years of balance sheets and income statements. Again, the purpose of this paper is to illustrate how dollar amounts of next year operating cash flow can be forecasted using only base year actuals and next year forecasts of credit sales, CGS, and the CCC (by DSO, DIO, DPO components). Proceeding...

After converting DSO, DIO, and DPO into their implied turnovers (summarized in Table 5), the reciprocal of the turnovers can be computed, which is shown in Table 6.

Table 5: Conversion of the Cash Conversion Cycle (CCC) Components as Expressed in Days to Turnovers

\begin{tabular}{|lccccc|}
\hline & $\frac{\text { Last Year Actual }}{\text { Days }}$ & & $\frac{\text { Turnovers }}{4.00}$ & $\frac{\underline{\text { Next Year Forecast }}}{\text { Days }}$ & $\frac{\text { Turnovers }}{52}$ \\
Day Sales Outstanding in Receivables (DSO) & 90 & 42 & 8.57 & 18 & 20.00 \\
Days CGS Outstanding in Inventory (DIO) & 48 & 7.50 & 66 & 5.45 \\
Day Purchases Outstanding in Payables (DPO) & & & & & \\
\hline
\end{tabular}

Table 6: Reciprocals Computations of the Cash Conversion Cycle Turnovers

\begin{tabular}{|c|c|c|c|c|}
\hline \multirow[b]{3}{*}{ Day Sales Outstanding in Receivables (DSO) } & \multicolumn{2}{|c|}{ Last Year Actual } & \multicolumn{2}{|c|}{ Next Year Forecast } \\
\hline & Turnovers & $\underline{\text { Reciprocals }}$ & Turnovers & Reciprocals \\
\hline & 4.00 & .2500 & 5.00 & .2000 \\
\hline Days CGS Outstanding in Inventory (DIO) & 8.57 & .1167 & 20.00 & .0500 \\
\hline Day Purchases Outstanding in Payables (DPO) & 7.50 & .1333 & 5.45 & .1833 \\
\hline
\end{tabular}

Recall from earlier in the paper, the algebraic manipulation by which to compute year-to-year changes in balance sheet account balances.

Year-to-year changes in the account balances of A/R, INV, and A/P, respectively, can be computed using the following formula: $\mathrm{F}-\mathrm{E}=[\mathrm{C} \times(\mathrm{D}-\mathrm{B})]+[(\mathrm{C}-\mathrm{A}) \mathrm{x} \mathrm{B}]$. This equation derives from the following relationships: $\mathrm{A} \times \mathrm{B}=\mathrm{E}$ and $\mathrm{C} \times \mathrm{D}=\mathrm{F}$, where:

$\mathrm{A}=$ income statement flow of Yr. 1

$\mathrm{B}=$ reciprocal of balance sheet account turnover for Yr. 1

$\mathrm{E}=$ balance sheet account ending balance of Yr. 1 
$\mathrm{C}=$ income statement flow of Yr. 2

$\mathrm{D}=$ reciprocal of balance sheet account turnover for Yr. 2

$\mathrm{F}=$ balance sheet account balance ending balance of Yr. 2

Using the data of this illustration, Yr. 1-to-Yr. 2 changes in the balance of $\mathrm{A} / \mathrm{R}, \mathrm{INV}$, and $\mathrm{A} / \mathrm{P}$ are calculated as shown in Table 7.

Table 7: Computation of the Effect of the Change in Accounts Balances

\begin{tabular}{|c|c|c|}
\hline \multirow[t]{2}{*}{$\Delta$ in the Receivables Balance effect } & $\begin{array}{l}=[\$ 110,000 \times(.20-.25)] \\
=[\$ 110,000 \times<.05>] \\
=\langle \$ 5,500> \\
=\langle \$ 3,000\rangle\end{array}$ & $\begin{array}{l}+[(\$ 110,000-\$ 100,000) \times .25] \\
+[(\$ 10,000 \times .25] \\
+\$ 2,500\end{array}$ \\
\hline & \multicolumn{2}{|c|}{ Negative sign means that Receivables balance will decline $\$ 3,000$} \\
\hline \multirow[t]{2}{*}{$\Delta$ in Inventory Balance effect } & $\begin{array}{l}=[\$ 62,700 \times(.05-.1167)] \\
=[\$ 62,700 \times<.0667\rangle] \\
=\langle \$ 4,180\rangle \\
=\langle \$ 3,865\rangle\end{array}$ & $\begin{array}{l}+[(\$ 62,700-\$ 60,000) \times .1167] \\
+[\$ 2,700 \times .1167] \\
+315\end{array}$ \\
\hline & \multicolumn{2}{|c|}{ Negative sign means that Inventory balance will decline $\$ 3,865$. } \\
\hline \multirow[t]{2}{*}{$\Delta$ in Payables Balance effect } & $\begin{array}{l}=[\$ 62,700 \times(.1833-.1333)] \\
=[\$ 62,700 \times .05] \\
=\$ 3,135 \\
=\$ 3,495\end{array}$ & $\begin{array}{l}+[(\$ 62,700-\$ 60,000) \times .1333] \\
+[\$ 2,700 \times .1333] \\
+\$ 360\end{array}$ \\
\hline & \multicolumn{2}{|c|}{ Positive sign means that Payables balance will increase $\$ 3,495$. } \\
\hline
\end{tabular}

The account balance changes can be used in an indirect method of Statement of Cash Flows to compute the forecasted dollar amount of operating cash flow for Yr. 2 (see Table 8).

Table 8: Use of the Statement of Cash Flow's Indirect Method Format to Forecast the Next Year (Yr. 2) Operating Cash Flow

\begin{tabular}{|lr|}
\hline Net Income (\$110,000 - \$62,700) & 47,300 \\
\pm non-Cash charges (e.g., depreciation) & 0 \\
\pm changes in current assets ...decrease in A/R & 3,000 \\
$\quad \ldots$. decrease in INV & 3,865 \\
\pm changes in current liabilities...increase in A/P & 3,495 \\
$=$ Operating Cash Flow & 57,660 \\
\hline
\end{tabular}

\section{CONCLUSIONS}

This paper has demonstrated, using a very simple case, how the time-denominated construct of the CCC can be algebraically manipulated to compute an inferred dollar-amount of operating cash flow. Table 9 summarizes the information required, as illustrated by our specific example, to forecast Yr. 2 operating cash flow of \$57,660. 
Table 9: Summary

\begin{tabular}{|c|c|c|}
\hline $\begin{array}{l}\text { From the following data... } \\
\text { Credit sales }\end{array}$ & $\frac{\text { Last Year Actual }}{\$ 100,000}$ & $\frac{\text { Next Year Forecast }}{\$ 110,000}$ \\
\hline Cost of Goods Sold(CGS) & $\begin{array}{l}\$ 60,000 \\
60.00 \%\end{array}$ & $\begin{array}{l}\$ 62,700 \\
57.00 \%\end{array}$ \\
\hline Day Sales Outstanding in Receivables (DSO) & 90 days & 72 days \\
\hline Days CGS Outstanding in Inventory (DIO) & 42 days & 18 days \\
\hline Total Days & 132 days & 90 days \\
\hline Day Purchases Outstanding in Payables (DPO) & - 48 days & $\underline{-66 \text { days }}$ \\
\hline Cash Conversion Cycle (CCC) & $\underline{84 \text { days }}$ & 24 days \\
\hline
\end{tabular}

\section{LIMITATIONS AND FUTURE RESEARCH}

Perhaps the primary limitation of this paper is that many real-world companies do not represent "a very simple case." This paper focused on a simple illustration of a company with inventory using the conversion cycle of cash paid for merchandise inventory, inventory sold to receivables, and receivables collected back to cash. A more thorough example would also illustrate the operating cash flow effects of selling general and administrative expenses. Also, a more thorough example, still, would illustrate the operating cash flow forecasting methodology presented in this paper in the context of a manufacturing company with its naturally more complicated cost flow. It can be shown that both of these complications can be dealt with within the confines of the methodology presented in this paper, but the paper does not demonstrate this.

Furthermore, for sophisticated, global, Fortune-500-type companies, it is sometimes difficult - if not impossible - for an outside analyst to reconstruct the operating section of an indirect-method statement of cash flows using the current account balance sheet changes as observed from the company's published annual report. Therefore, the authors concede that the methodology presented in this paper may be of limited use to the manager of the large sophisticated company. However, we maintain that for the "simple company," this methodology can be helpful in converting the intuitively appealing CCC approach to managing a company's operating cycle to one which affords the opportunity to forecast estimated dollar amount of operating cash flows.

It is the dollar amount of operating cash flows, and the ability to accurately predict them, that is of critical importance to the manager of the firm. So, the CCC and its changes tells the practical business manager only so much. He or she knows that a decreasing CCC is a good thing - operating cash flow is speeding up. For a growing, profitable business, one could ask the question, "Does this imply that operating cash flow in dollar amount must necessarily be increasing for this company?" (Hint to correct answer - "not necessarily") Conversely, the conventional wisdom is that an increasing CCC is a bad thing - operating cash flow is slowing down. Does this imply that the dollar amount of operating cash flows are necessarily decreasing? (Hint to correct answer, again "not necessarily"). These perhaps ambiguous answers are fodder for future research.

\section{AUTHOR INFORMATION}

Richard Griffin is a professor of accountancy at the University of Tennessee - Martin. He has a PhD in accountancy from the University of Mississippi. His research interests are in the areas of assessing quality of earnings, AACSB accreditation issues, and issues regarding accounting curriculum and the Uniform Certified Public Accounting Exam. E-mail: rgriffin@utm.edu

B. Wynne Griffin is a Senior Manager of Financial Planning and Analysis at Fareva. He previously worked at E.I. DuPont and PricewaterhouseCoopers LLP. E-mail: bgriffin.richmond@ fareva.com 
Ken VanVuren is an associate professor of accountancy at the University of Tennessee - Martin. His PhD is in accountancy from the University of Mississippi. His research interests are in the areas of managerial accounting decision-making, business ethics, and pedagogical effectiveness in business education. E-mail: vanvuren@utm.edu (Corresponding author)

\section{REFERENCES}

1. Akgun, M., \& Gurunlu, M. (2010). Cash to cash cycle as an integral performance metric in supply chain management: A theoretical review. The IUP Journal of Supply Chain Management, 2(1\&2), 7-20.

2. Brigham, E. F., \& Houston, J. F. (2013). Fundamentals of financial management. Stamford, CT: Cengage.

3. Filbeck, G., \& Krueger, T. M. (2005). An Analysis of working capital management results across industries. Mid-American Journal of Business, 20(2), 11-18.

4. Gentry, J. A., Vaidyanathan, R., \& Lee, H. W. (1990). A weighted cash conversion cycle. Journal of the Financial Management Association, 19(1), 90-99.

5. Griffin, R. B., Griffin, B. W., \& VanVuren, K. W. (2009). The additive DuPont model: An alternative approach to analyzing company performance. International Journal of the Academic Business World, 3(1), 29-38.

6. Lee, L. F. (2012). Incentives to inflate reported cash from operations using classification and timing. The Accounting Review, 87(1), 1-33.

7. Mills, J. R., \& Yamamura, J. H. (1998). The power of cash flow ratios. Journal of Accountancy, March. 5361 .

8. Ohlson, J. A., \& Aier, J. K. (2009). On the analysis of firms' cash flows. Contemporary Accounting Research, 26(4), 1091-1114.

9. Reider, R. (2010). Auditing your cash conversion. Journal of Corporate Accounting and Finance, 21(4), 53-59.

10. Richards, V. D., \& Laughlin, E. J. (1980). A cash conversion cycle approach to liquidity analysis. Financial Management, 9(1), 32-38.

11. Ross, S. A., Westerfield, R. W., \& Jordan, B. D. (2013). Fundamentals of corporate finance. New York: McGraw-Hill.

12. Strischek, D. (2001). A banker's perspective on working capital and cash flow management. Strategic Finance, 83(4), 38-45.

13. White, H. (2004). Financial statement analysis, forecasting and budgeting: An integrative teaching approach. Journal of Accounting \& Finance Research, 12(5), 49-61. 